have both dyskaryosis and warts. A group with both dyskaryosis and warts is not included in the hypothetical example. If it had been, assuming that dyskaryosis and warts were independent risk factors for CIN, the relative risk for the group with both dyskaryosis and warts would be $16 \times 4=64$. This would imply that $100 \%$ of the group with both dyskaryosis and warts would have CIN. The $2 \times 2$ table would now be:-

$\begin{array}{lll} & \text { CIN } & \text { No CIN } \\ \text { Warts } & 55 & 45 \\ \text { No Warts } & 20 & 30\end{array}$

giving a relative risk of 1.83 -more than 10 times the $0 \cdot 17$ obtained by Dr Renton and his colleagues from their inappropriate example.

We thank your correspondents for their combined interest in our paper.

1 Jenkins D, Tay SK, McCance DJ, et al. Histological and immunocytochemical study of cervical intraepithelial neoplasia (CIN) with associated HPV6 and HPV16 infections. F Clin Pathol 1986;39:1 177-80.

2 Robertson AJ, Anderson JM, Swanson BECH, et al. Observer variability in histopathological reporting of cervical biopsy specimens. $\mathcal{f} \mathrm{Clin}$ Pathol 1989;42:231-8.

\section{National STD trends in Zambia 1987-89}

In their review of national STD trends in Zambia, Matondo concludes that there has been a decline in STDs since 1987. ${ }^{1}$ This, it is stated, has occurred in spite of the increase in the number of STD clinics.

I wish to point out, however, that the data presented do not make a strong case for reaching this conclusion. The figures presented are absolute numbers of total cases and number of cases of each particular condition. This does not clearly show any shif in any direction as the data are influenced by various qualitative and quantitative factors. The assertion that because all clinics reported a decline suggests a genuine decline in STDs is not valid and needs clarification. This assertion can only be proved by establishing that a similar decline in outpatient attendances did not occur. It is known, for instance, that the economic situation in Zambia worsened during the period under study. This resulted, as expected, in a reduction in the resources allocated for health services. Consequently, there was a reduction in the availability of drugs and personnel with a subsequent decrease in hospital utilisation in some years. Health facility attendance for all conditions declined over the years though not uniformly. Although a decline in numbers of STD attendances did occur during the period in question, there was no decline if taken as a proportion of the total number of attendances. The decline reported is therefore an apparent decline and not a genuine one.

Individuals who do not seek medical care from health centres and hospitals go elsewhere, as Dr. Matondo rightly points out. It is necessary, therefore to study STD trends among private practitioners, traditional healers and other informal health workers before being conclusive on declines. It is possible that there is an inverse relationship between the number of people who attend hospitals and those seek treatment elsewhere.

Although the AIDS control programme in Zambia was established in 1986 and the
STD programme in 1980 , it was not until 1988 that massive health education campaigns were initiated. It is not likely that there were positive outcomes of these initiatives as early as 1988 . As STD trends can be used as a surrogate marker for sexual behaviour change, trends in HIV infection also can be used as a proxy indicator of STD trends. Contrary to Matondo's findings, HIV surveillance data have shown increases in sero-prevalence rates in antenatal clinic attenders and blood donors during that period. ${ }^{2}$

In a paper presented at the International Conference on AIDS in Africa, Kinshasa, we reviewed data from STDs in Zambia and were able to conclude that it was possible to infer wrongly that a decline had occurred if the data did not take account of various quantitative and qualitative factors. ${ }^{3}$ In addition we showed that when rates are calculated using out-patient attendances as denominators fluctuations, and not a steady decline in trends, is noted.

It is for this reason that the data presented should have considered rates and not absolute numbers. In calculating the rates, the total number of individuals attending a particular site for any reason should be taken as a denominator. This is so that the biases introduced by factors that affect hospital services utilisation and provision are considered.

I wish to suggest, therefore, that Matondo re-analyse his data and use out-patient attendance for each period as a denominator. This will allow comparisons of rates as opposed to absolute numbers. In addition we suggest that tests of significance are performed on the data to validate whether any changes in trends are statistically significant and present a genuine decline in STD trends.

Epidemiologist AIDS Control ProORGE TEMBO Emme PO Box 6,

1 Matondo P. National STD trends in Zambia: 1987-89 Genitourin Med 1992;68:192-8 2 Tembo G. Hira S. Epidemiological review of Conference on AIDS, 1989, Montreal, Canada.

3 Tembo G Hira, S, Van Praag E. Monitoring STD trends: quantitative and qualitative issues. $V$ International conference on AIDS in Africa, Kinshasa, 1990.

\section{HIV infection in Tirupathi, India}

I refer to the comments of Ravi Sockanathan, Genitourin Med, 1992;68:199. I must point out that vast numbers of non-Hindus also exist in Tirupathi and these include Muslims, Christians and others. It is therefore completely inappropriate to single out Hindus. Also, in a country with so much illiteracy as India, posters on sexual topics would be ill received. Television might help but what is really needed is education of the population as a whole. In the field of genitourinary medicine in particular much attention needs to be paid to differences between cultures.

S THARAKARAM The Royal Infirmary New Durham Road, Sunderland SR2 $7 F E, U K$

Sockanathan replies:

I refer to the comments of Dr S Tharakaram and value his suggestions, indicating that TV programmes and education of the population as a whole would raise the public awareness of the prevalence of HIV infection in Tirupathi and South India. However, he has failed to appreciate that holiday makers from Europe who are unaware of the prevalence of the disease in these areas, will certainly not be influenced by health education campaigns. Radio and television programmes may be a source of information for the local population only. Therefore the lay press published in the western world indicating the prevalence of the infection in these areas will certainly increase the awareness amongst holiday makers and some pilgrims!

Illiteracy in India, should not form a barrier for health education programmes. A standard protocol for the prevention and control of sexually transmitted diseases ${ }^{1}$ should be followed in the tropics and developing countries as recommended by the World Health Organisation.

Although the epidemiology health education programmes of sexually transmitted diseases in the tropics vary from that in the developing countries, ${ }^{2}$ it is well known that British yardsticks are commonly used in many parts of the world including India.

$$
\begin{array}{r}
\text { of the world including India. } \\
\text { RAVI SOCKANATHAN } \\
\text { Department of Genito-urinary Medicine } \\
\text { United Leeds Teaching Hospitals } \\
\text { Leeds General Infirmary } \\
\text { Leeds LS1 3EX, UK }
\end{array}
$$

1 Bennett FJ. Control of sexually transmitted diseases in the tropics and developing countries. In "Sexually Transmitted Diseases in the Tropics" Osoba AO, (ed). Bailliere; London. 1987.

2 Wilcox RR. VD education in developing countries. A comparison with developed countries. Br $\mathcal{F}$ Venereal Dis 1976;52:88.

Exophytic cervical warts-an indication for colposcopy?

In their recent paper, Evans et al conclude that external anogenital warts are not a risk for subclinical cervical HPV infection or for $\mathrm{CIN}$ and therefore not an indication for colposcopy. 1 In contrast to external exophytic warts, cytological evidence of cervical HPV infection was strongly associated with all grades of CIN. The authors suggest that external exophytic anogenital warts may in fact have a protective effect on the genesis of CIN. However, Evans et al make no comment on the relationship of exophytic cervical warts, as distinct from subclinical cervical HPV infection, to CIN.

Approximately $6 \%$ of women with genital warts may have exophytic cervical warts. The practice at this unit is to perform colposcopy on all women with clinically apparent exophytic cervical warts regardless of the result of cervical cytology. In a preliminary study we reviewed the cytological, colposcopic and histological findings of all patients who had colposcopy performed primarily for this indication. Thirty four patients were identified over a 6 month period, of whom $82.4 \%$ had concomitant vulval warts. Only four (11.7\%) women had cytological evidence of HPV infection. Dyskaryosis was found in $9 / 34(26.5 \%)$ Twelve patients had normal cytology, two of whom had CIN (grade 2) on histology (negative predictive value $83 \cdot 3 \%$ ). Nineteen patients had low grade smears (inflammatory/borderline, wart virus infection, mild dyskaryosis) of whom four had CIN 1 and two CIN 2. Overall $9 / 34(26 \cdot 5 \%)$ women 